\title{
Variable-Thermoinsulation Garments With a Microprocessor Temperature Controller
}

\author{
Agnieszka Kurczewska \\ Central Institute for Labour Protection - National Research Institute, Łódź, Poland \\ Jacek Leśnikowski \\ Faculty of Textile Engineering and Marketing, Technical University of Łódź, Poland
}

This paper presents the concept of active variable thermoinsulation clothing for users working in low temperatures. Those garments contain heating inserts regulated by a microprocessor temperature controller. This paper also presents the results of tests carried out on the newly designed garments.

thermoregulation temperature controller human body

textronic system for temperature control smart textiles

\section{INTRODUCTION}

In low temperature, the human body is at risk of rapid heat loss $[1,2,3,4,5]$. Clothes that provide passive protection against hypothermia have long been used to overcome this problem. Such a solution, however, has a serious disadvantage: garments that provide a high level of insulation are usually thick and stiff, limiting the user's freedom of movement [6]. Research has been conducted in the field of construction of new multifunctional textiles [7, 8]. The development of textiles that conduct electric current has led to numerous attempts at using them in garments providing active thermoregulation. However, small, lightweight energy sources cannot generate the required high levels of energy. Thus, those garments cannot be used on a large scale. In view of considerable progress in this field and the development of miniature textronic temperature control systems, the Central Institute for Labour Protection - National Research Institute (CIOP$\mathrm{PIB}$ ), in co-operation with the Department for
Automation of Textile Processes of the Technical University of Łódź, undertook research aimed at constructing a temperature controller for what will be called active clothing in this article. Such clothing is made of smart textiles and has microprocessor temperature control, thus combining a high level of thermal comfort with low energy consumption that can be provided by a small, lightweight energy source.

\section{AIM AND SCOPE}

The primary aim of this research was to develop a model of protective clothing designed for work in a cold environment. Such clothing would actively react to temperature changes, adjusting the level of thermoinsulation so as to provide conditions approximating as closely as possible thermal comfort for the user.

CIOP-PIB studies on hand cooling under low temperature conditions [9] at workstands in closed premises have shown in what industries exposure to low temperatures is common. They are listed,

Correspondence and requests for offprints should be sent to Agnieszka Kurczewska, Central Institute for Labour Protection - National Research Institute, Wierzbowa 48, 90-133 Łódź, Poland. E-mail: <agkur@ciop.lodz.pl>. 
TABLE 1. Data on Typical Low-Temperature Workstands in Closed Premises

\begin{tabular}{lcc}
\hline Industry & Temperature Range & Work Duration \\
\hline $\begin{array}{l}\text { Meat processing (including production, processing and } \\
\text { storage of different types of meat, and production of }\end{array}$ & $-2-14{ }^{\circ} \mathrm{C}$ & $\leq 8 \mathrm{hrs}$ \\
meat-based products) & & $\leq 8 \mathrm{hrs}$ \\
Processing and storage of fish and seafood & $-2-10^{\circ} \mathrm{C}$ & $4-7 \mathrm{hrs}$ \\
Production and processing of vegetables and fruit & $<10^{\circ} \mathrm{C}$ & $\leq 7 \mathrm{hrs}$ \\
Wholesale trade in meat, meat products, fish, etc. & $-2-14^{\circ} \mathrm{C}$ & $4-6 \mathrm{hrs}$ \\
Storage and distribution of food products: cold stores & $-20-4{ }^{\circ} \mathrm{C}$ & $1-8 \mathrm{hrs}$ \\
Freezing tunnels & $-24^{\circ} \mathrm{C}$ & - \\
Production of condensed gases & potential exposure to liquid splashes \\
\end{tabular}

together with typical duration of exposure and temperature ranges, in Table 1 [2].

Workers in cold stores who handle food products and bottle condensed gases are exposed to the most extreme everyday working conditions. Whereas work in cold stores is associated with similar duration of exposure to cold every day, bottling condensed gases involves varied duration.

Recently there has been increased interest in cryogenic chambers used in treating many diseases and in wellness centres. The temperature in such chambers is approximately $-120{ }^{\circ} \mathrm{C}$. Appropriate protection of chamber operators, who must enter them several times a day, is an important problem.

Workstands associated with exposure of staff to low temperatures also include outdoor workstands in winter, such as in various rescue services, the building industry, transport, forestry and fishing, where workers are exposed to low temperature, often in combination with strong winds. It should be emphasized that the performance of many tasks in those sectors is often more difficult because commonly used protective clothing with high thermal insulation is thick and heavy [10, 11]. Outdoor work usually lasts many hours and involves variable physical activity.

\section{DESCRIPTION OF CLOTHING}

The clothing set consisted of a jacket and waisthigh trousers supported with braces fastened with Velcro ${ }^{\circledR}$ brand tape (Figure 1). Its size conformed to Standard No. EN 340:2003 [12]: body height $182-188 \mathrm{~cm}$, chest circumference $104-108 \mathrm{~cm}$ and waist $96-100 \mathrm{~cm}$.
The jacket was straight, below hips length, with an adjustable drawstring at the bottom. It covered the upper part of the trousers providing tightness of the garment against the wind. The sleeves of the jacket and the trouser legs had cuffs fastened with Velcro ${ }^{\circledR}$ brand tape for adjusting tightness. The garment's good fit made it possible to eliminate the chimney effect, i.e., a natural tendency of heat to flow upwards, which deteriorates the thermoinsulating properties of clothing.

There were zips at the sides of the trouser legs; they were covered with fabric fastened with Velcro ${ }^{\circledR}$ brand tape, which facilitated putting the trousers on and taking them off. They also improved tightness. The clothing set was made of a system of four layers of material with thermal resistance of $0.2 \mathrm{~m}^{2} \mathrm{~K} / \mathrm{W}$, i.e., lower insulation than required for light work with metabolic rate of $110 \mathrm{~W} / \mathrm{m}^{2}$ in $-24{ }^{\circ} \mathrm{C}$ assuming that the applied heating system should "increase" this insulation to a sufficient level.

The jacket contained four $20 \times 20 \mathrm{~cm}$ heating inserts, two at the level of the chest and two inside the sleeves; the trousers contained two heating inserts at the level of the lower legs [13]. For the purpose of the study, all the heating inserts were placed in specially designed pockets to make potential modifications possible. Placing the heating inserts in the sleeves and the trouser legs made it possible to improve the thermal insulation of the parts of the body which are at the highest risk of cooling. The measurement and control system was placed in the internal pocket in the right front part of the jacket. Along the circumference of the lower part of the jacket, there were pockets for the power supply system (rechargeable cells). 


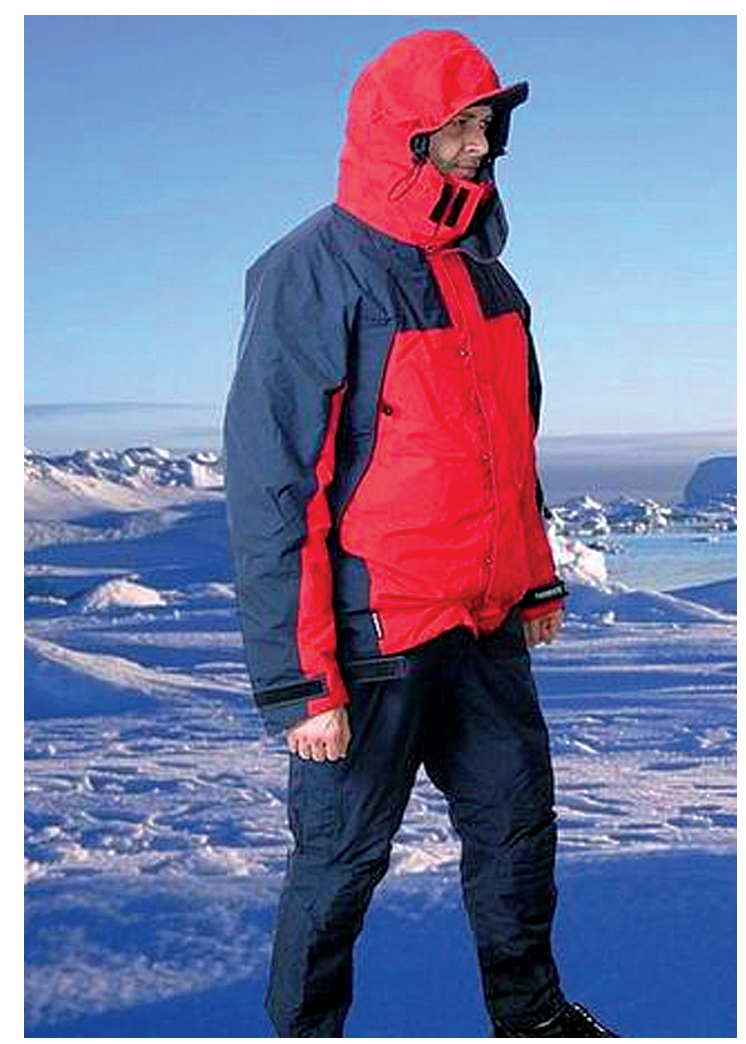

Figure 1. Clothing protecting against the cold developed in this study.

\section{TEMPERATURE CONTROLLER}

The Tilmet 76 type temperature controller, developed in the Department for Automation of Textile Processes of the Technical University of Łódź, is equipped with an advanced miniature control device that makes it possible (a) to measure temperature outside the garment, (b) to measure skin temperature in two places of the body and (c) to make an optional measurement of the pulse. On the basis of measurement data, following a preset algorithm, the temperature controller decides whether to switch on or off the power supply to the heating inserts.

Figure 2 is a diagram of the regulator. KTY 82-150 (Philips, The Netherlands) semiconductor temperature sensors were used to measure outside temperature and skin at the level of the scapula and the clavicle. Signals from these sensors were transferred to the signal conditioning block input, where they were amplified. After amplification, the signals were transferred to the input of a 16-bit Sigma-Delta type analog-todigital converter, part of an AduC824 (Analog Devices, USA) microcontroller, which was the principal element of the temperature controller. The microcontroller measured temperature with a frequency preprogrammed by the subject. Cyclical pulse measurements were also made. Pulse was measured with a Polar S-610 Precision Toolkit (Polar, Finland) transmitter-receiver. The pulse sensor, a belt surrounding the chest, had a separate power supply. Data from the sensor were transmitted as radio waves to the receiver. The receiver, through its series output, transmitted them to the series input of the microcontroller which, on the basis of measurement data and the preset algorithm, decided whether to switch on or off the power supply to the heating inserts.

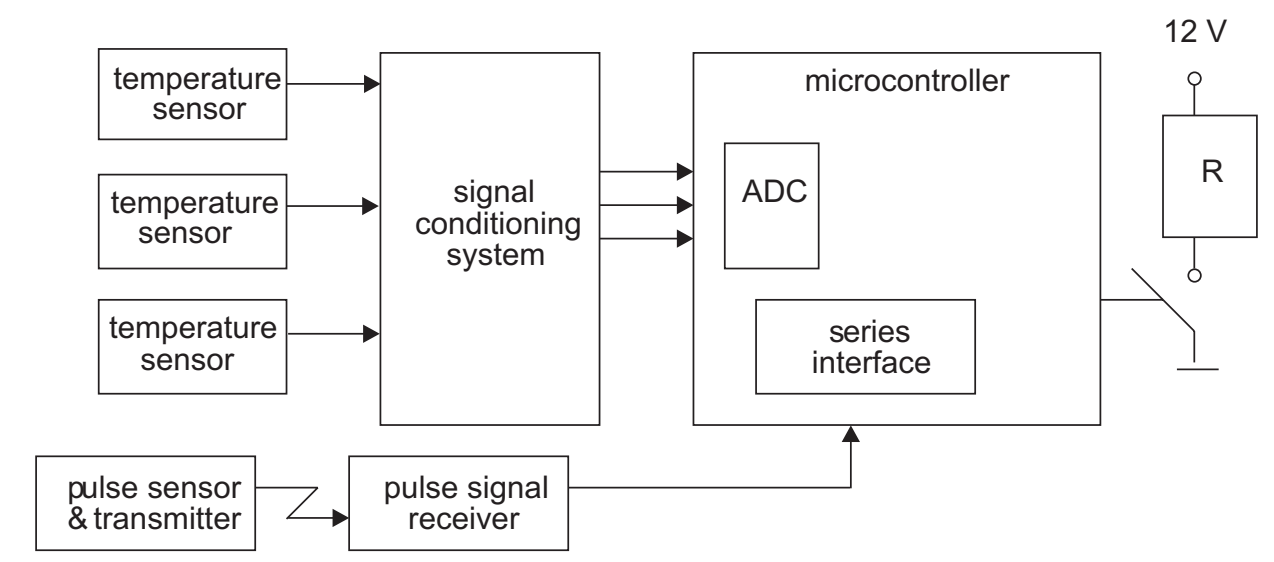

Figure 2. Diagram of the temperature controller. Notes. ADC—analog-to-digital converter, R-heating inserts. 
The algorithm for controlling heating inserts was developed in CIOP-PIB; it consists of eight conditions:

1. $T_{\mathrm{C}}-T_{0 \mathrm{C}}<T_{\min }$ and $v-v_{0}<z_{1}$

2. $T_{\mathrm{S}}-T_{0 \mathrm{~S}}<T_{\min }$ and $v-v_{0}<z_{1}$

3. $T_{\mathrm{C}}-T_{0 \mathrm{C}}<T_{\min }$ and $v-v_{0}>z_{2}$

4. $T_{\mathrm{S}}-T_{0 \mathrm{~S}}<T_{\min }$ and $v-v_{0}>z_{2}$

5. $T_{\mathrm{C}}-T_{0 \mathrm{C}}>T_{\max }$ and $v-v_{0}<z_{1}$

6. $T_{\mathrm{S}}-T_{0 \mathrm{~S}}>T_{\max }$ and $v-v_{0}<z_{1}$

7. $T_{\mathrm{C}}-T_{0 \mathrm{C}}=0$ and $v-v_{0}<\mathrm{z}_{1}$ and $T_{\mathrm{z}}<T_{\text {out }}$ and $L_{T 2}>5 \mathrm{~min}$

8. $T_{\mathrm{s}}-T_{0 \mathrm{~s}}=0$ and $v-v_{0}<\mathrm{z}_{1}$ and $T_{\mathrm{z}}<T_{\text {out }}$ and $L_{T 2}>5 \mathrm{~min}$

where $T_{0 \mathrm{C}}$-baseline skin temperature on the clavicle, $T_{0 \mathrm{~S}}$-baseline skin temperature on the scapula, $T_{\mathrm{C}}$-final skin temperature on the clavicle, $T_{\mathrm{S}}$-final skin temperature on the scapula, $T_{\mathrm{z}}$ - outside temperature, $v_{\mathrm{o}}$-baseline heart rate (HR), $v$-final HR, $z_{1}$-preset HR, $z_{2}$-preset HR, $L_{T 2}$ - duration of outside temperature change, $T_{\min }$ - first preset skin temperature on the scapula/clavicle, $T_{\max }$ - second preset skin temperature on the scapula/clavicle, $T_{\text {out }}$-preset outside temperature.

The interval between cyclical measurements and the $T_{\min }, T_{\max }, z_{1}, z_{2}$ and $T_{\text {out }}$ parameters can be set to values selected by the subject. The temperature controller measures temperature and pulse rates cyclically, obtaining a series of temperature and pulse values marked as baseline and final values. Then the microcontroller, on the basis of conditions just presented, decides to switch the heating on or off. The conditions are formulated so as to ensure that heating is switched on at the moment when the decrease in skin temperature at the measurement sites exceeds the preset values. In the case of a temperature increase, heating is switched off. Outside temperature is also monitored; when it exceeds the preset value of $T_{\text {out }}$, heating is switched off. The purpose of additional pulse monitoring is to detect increased physical exertion.

\section{METHODOLOGY OF TESTING ACTIVE GARMENTS}

Six male subjects tested the newly designed active thermoinsulating clothing sets. They were healthy, physically fit men aged $37 \pm 3$ years, $176 \pm 4 \mathrm{~cm}$ tall, with similar body constitution. Correct selection of the subjects was confirmed by medical examinations carried out before the tests. The subjects were fully informed of the tests' purpose and procedures. The tests were carried out in real cold-store conditions, in a chamber where the temperature was $-24 \pm 2{ }^{\circ} \mathrm{C}$.
The aims of the tests were as follows:

- to check the correct operation of the measurement and control system;

- to assess objectively the clothing set based on measurement results;

- to obtain a subjective assessment of the clothing set; and

- to demonstrate differences in thermal comfort between subjects working in active, heated clothing sets and those in clothing sets providing the same insulation parameters without a heating system (hereafter called passive).

\subsection{Thermal and Physical Load}

The subjects did two versions of exercise each: light work (LW; metabolic rate: $110 \mathrm{~W} / \mathrm{m}^{2}$ ) at ambient temperature of $-24{ }^{\circ} \mathrm{C}$; and $10 \mathrm{~min}$ of moderately hard work (MW; metabolic rate: $165 \mathrm{~W} / \mathrm{m}^{2}$ ) at ambient temperature of $-24{ }^{\circ} \mathrm{C}$, followed by a period of light work $\left(110 \mathrm{~W} / \mathrm{m}^{2}\right)$. LW consisted of walking at $0.5 \mathrm{~m} / \mathrm{s}$, whereas MW of walking at $1 \mathrm{~m} / \mathrm{s}$ and carrying $8-\mathrm{kg}$ packages for $3 \mathrm{~m}$. The two versions had two variants each: the subjects wore either a clothing set with constant thermoinsulation with the heating system switched off (reference garment; variant I) or a clothing set with variable thermoinsulation with the heating system switched on (variant II).

Before the tests, each subject's arterial blood pressure and HR were measured. Then, skin temperature sensors (thermocouples manufactured by Ellab, Denmark) were placed on the 

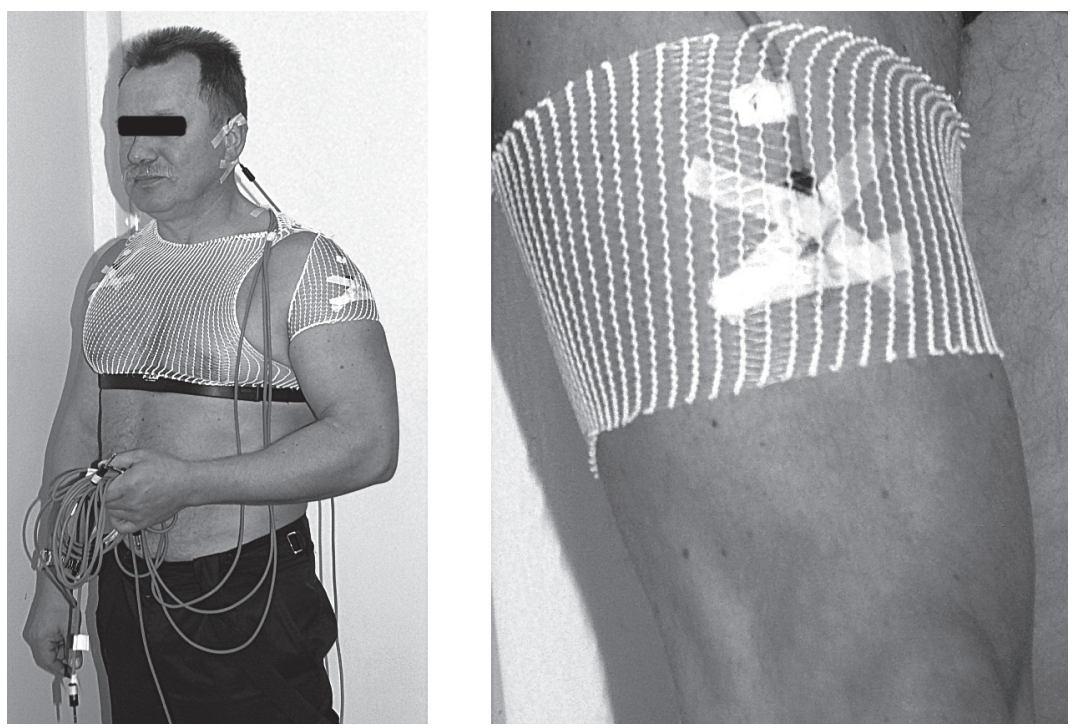

Figure 3. Temperature sensors.

chest, shoulder, scapula and thigh (Figure 3). An HR recorder (Polar S-610 Precision Toolkit) was placed on the chest. Core temperature was measured in the external auditory canal $[14,15$, 16].

The participant was then dressed in the tested clothing set, i.e., undergarment clothing with miniature temperature sensors, and an outer garment (variant I or II).

Using the temperature controller interface, the parameters of the reaction algorithm were set to make the system react to every change in the subject's skin temperature by $0.2^{\circ} \mathrm{C}$ and to switch itself on if the temperature outside fell below $0{ }^{\circ} \mathrm{C}$.

Then the subject entered the cold room, where he did the exercise according to the instructions. The test was discontinued when there was a considerable heat loss, i.e., subjects reported feeling cold or core temperature fell below $36{ }^{\circ} \mathrm{C}$. After each test, the subject's blood pressure and HR were recorded. During the tests, skin temperature was measured on the right side of the chest, on the left scapula, the left shoulder and the right thigh. HR and core temperature were measured, too.

Temperature was measured at 5-min intervals, whereas HR on a continuous basis. Subjective perception of temperature was recorded using Fanger's scale in conformity with Standard No. EN ISO 7730:2005 [17], with numeric scores ranging from -4 to +4 corresponding to specific descriptive subjective assessments (Table 2). This was also done at 5-min intervals.

TABLE 2. Fanger's Scale for Subjective Assessment of Thermal Sensation [16]

\begin{tabular}{lc}
\hline Numeric Score & Descriptive Assessment \\
\hline+4 & very hot \\
+3 & hot \\
+2 & warm \\
+1 & a little warm \\
0 & natural \\
-1 & a little cold \\
-2 & rather cold \\
-3 & cold \\
-4 & very cold \\
\hline
\end{tabular}

\subsection{Treatment of Data}

Statistical differences were determined using analysis of variance (ANOVA) $(p=.05)$ taking conditions of test performance into consideration. Homogeneity of a variance was estimated with the Levene test. Additionally, the differences among skin temperatures for tests in clothing with or without active thermoinsulation in the two variants of the test were assessed with the NIR test.

\subsection{Test Results}

The primary aim of the tests was to assess the correct functioning of the temperature control system. When the subject in clothing with the 
active thermoregulation system passed from the room where it was $10^{\circ} \mathrm{C}$ to the one where it was $-24{ }^{\circ} \mathrm{C}$, the system switched itself on after $\sim 1$ min. When skin temperature increased by $0.2{ }^{\circ} \mathrm{C}$, the system switched itself off and started to work again when skin temperature fell by $0.2^{\circ} \mathrm{C}$.

\subsection{Skin Temperature}

The results of skin temperature measurements (averaged for the 6 subjects) during $30 \mathrm{~min}$ of the LW (Figures 4a and 4b) and MW versions of the test (Figures $5 a$ and $5 b$ ) as well as the results of the subjective assessment of the clothing (Figure 6) follow.

Table 3 presents the slopes of lines illustrating functions of temperature changes in time for the four measurement sites and the two versions of the test.

\subsection{Subjective Responses}

An analysis of the subjective assessment of thermal sensation conducted with Fanger's scale [16] for the LW version of the test revealed considerable differences in thermal comfort

(a)

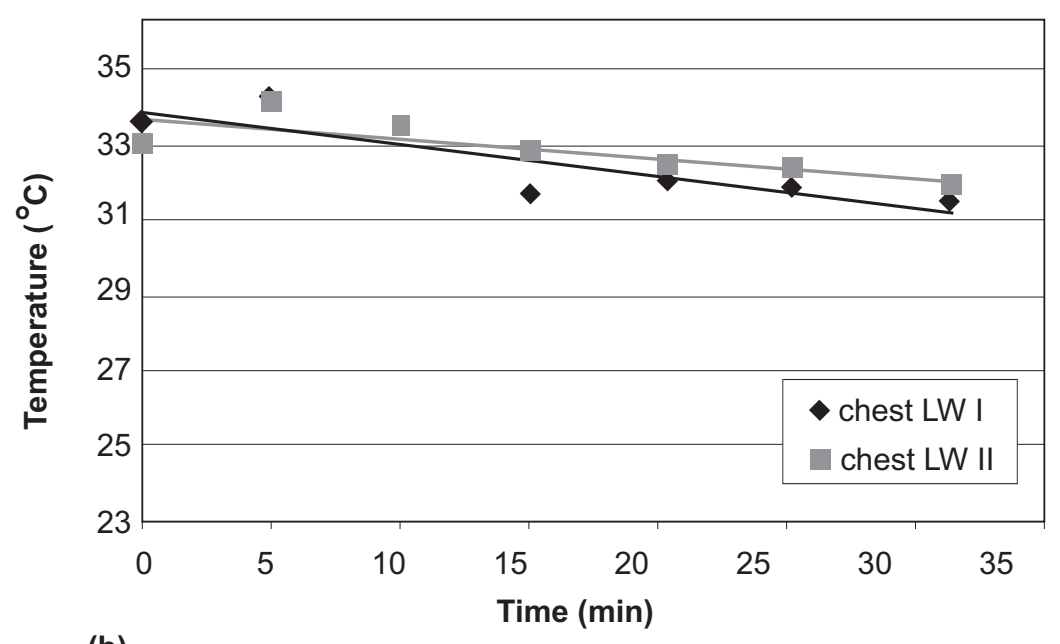

(b)

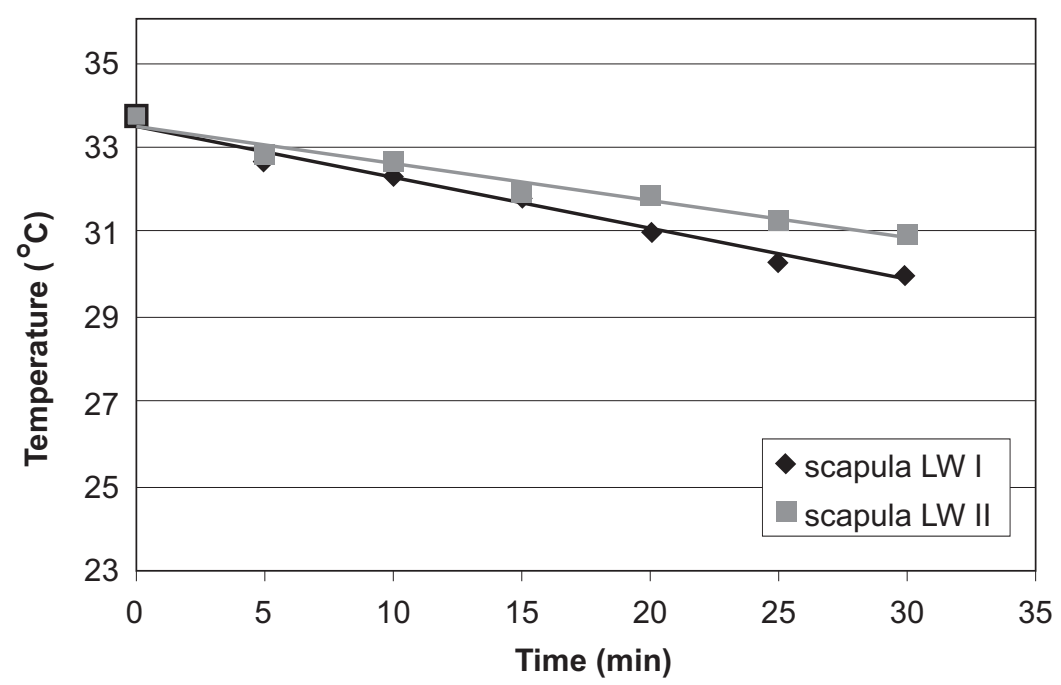

Figure 4a. Temperature changes in time for light work: (a) chest, (b) scapula. Notes. $n=6$; LWI-light work, heating system off; LWII-light work, heating system on. 
(c)

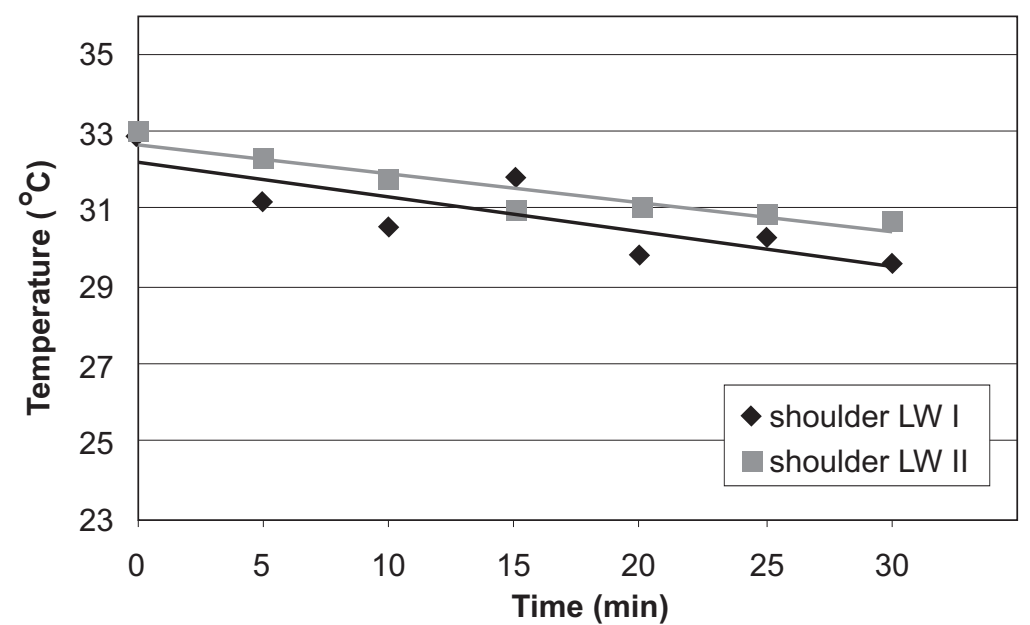

(d)

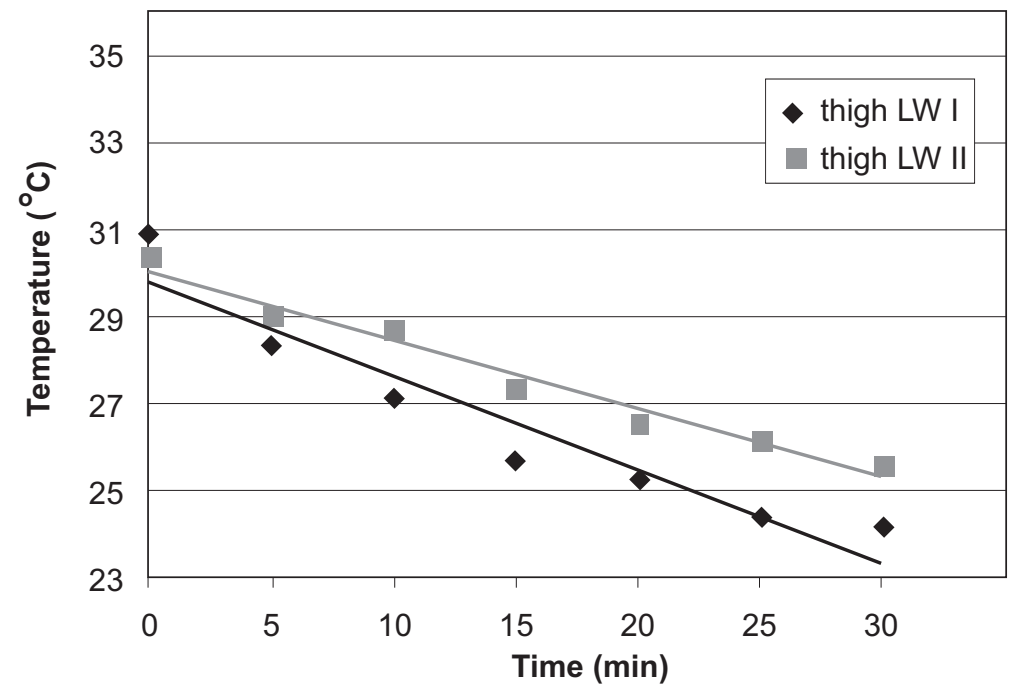

Figure 4b. Temperature changes in time for light work: (c) shoulder, (d) thigh. Notes. $n=6$; LWI—light work, heating system off; LWII-light work, heating system on.

TABLE 3. Slopes of Lines Illustrating Functions of Temperature Changes in Time for 4 Measurement Sites for Light and Moderately Hard Work in Passive and Active Clothing

\begin{tabular}{lllll}
\hline & \multicolumn{4}{c}{ Slope of a Straight Line } \\
\cline { 2 - 5 } Measurement Sites & $\boldsymbol{a}_{\text {LWI }}$ & $\boldsymbol{a}_{\text {LWII }}$ & $\boldsymbol{a}_{\text {MW I }}$ & $\boldsymbol{a}_{\text {MW II }}$ \\
\hline Chest & -0.09 & -0.06 & -0.10 & -0.05 \\
Scapula & -0.12 & -0.08 & -0.08 & -0.07 \\
Shoulder & -0.08 & -0.07 & -0.11 & -0.09 \\
Thigh & -0.20 & -0.15 & -0.16 & -0.15 \\
\hline
\end{tabular}

Notes. LWI—light work, heating system off; LWII—light work, heating system on; MWI—moderately hard work, heating system off; MWII-moderately hard work, heating system on. 
(a)

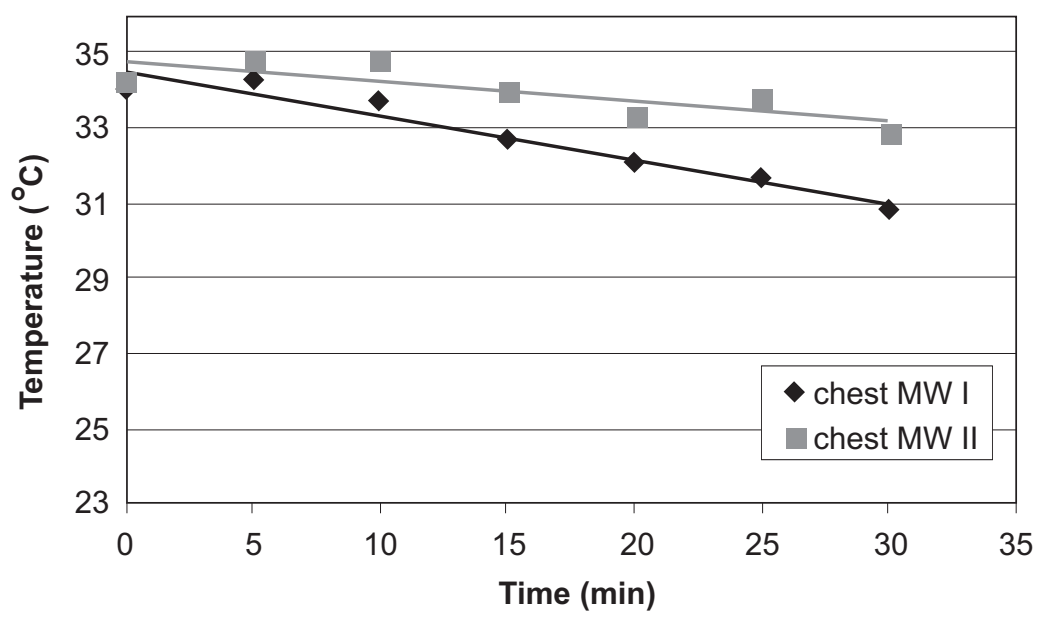

(b)



(c)

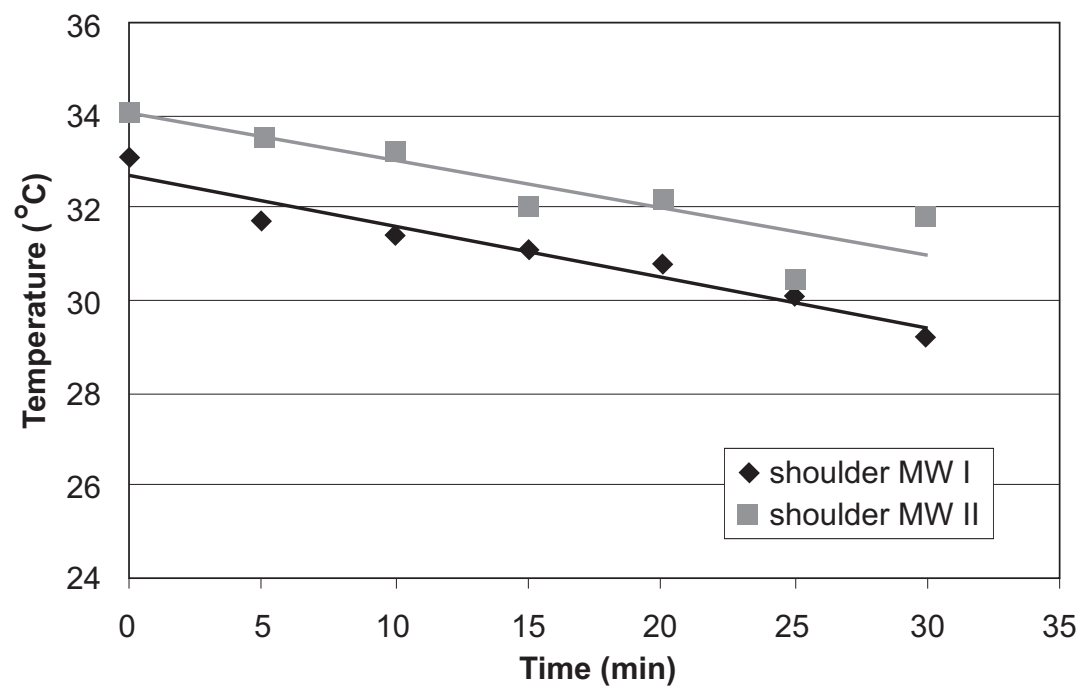

Figure 5a. Temperature changes in time for moderately hard work: (a) chest, (b) scapula, (c) shoulder. Notes. $n=6$; MWl—moderately hard work, heating system off; MWII—moderately hard work, heating system on. 
(d)

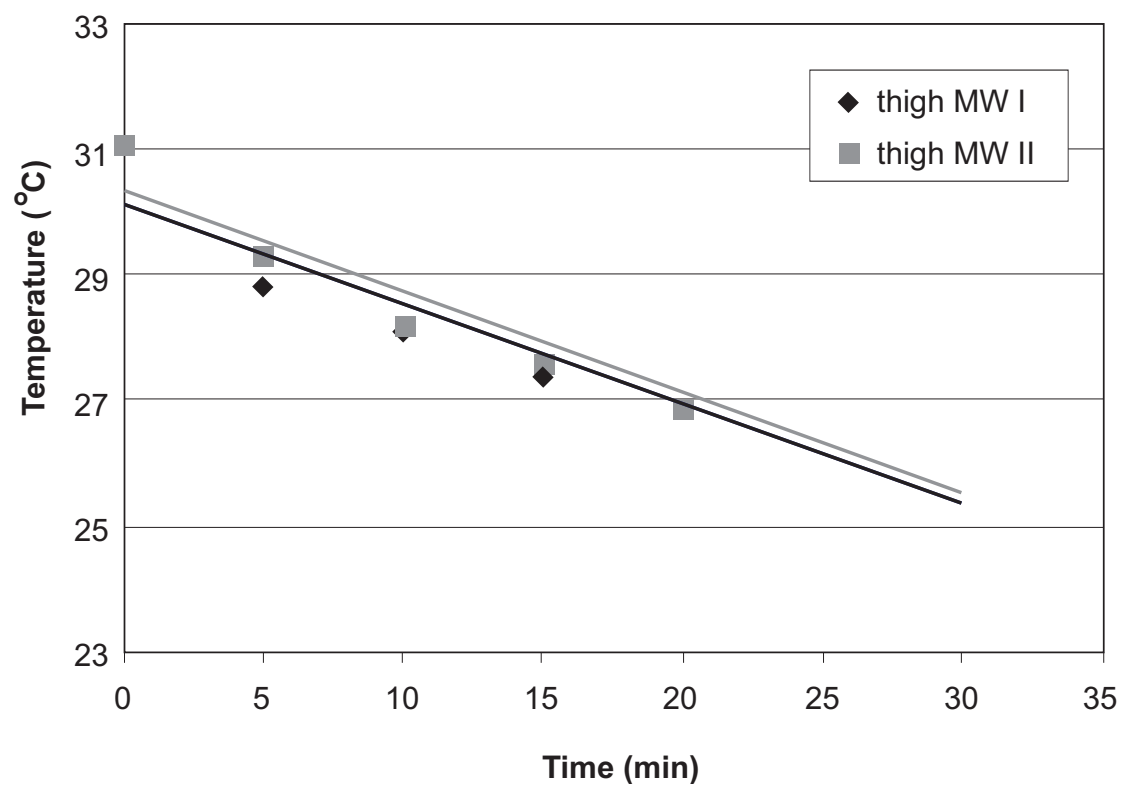

Figure 5b. Temperature changes in time for moderately hard work: (d) thigh. Notes. $n=6$; MWI—moderately hard work, heating system off; MWII—-moderately hard work, heating system on.

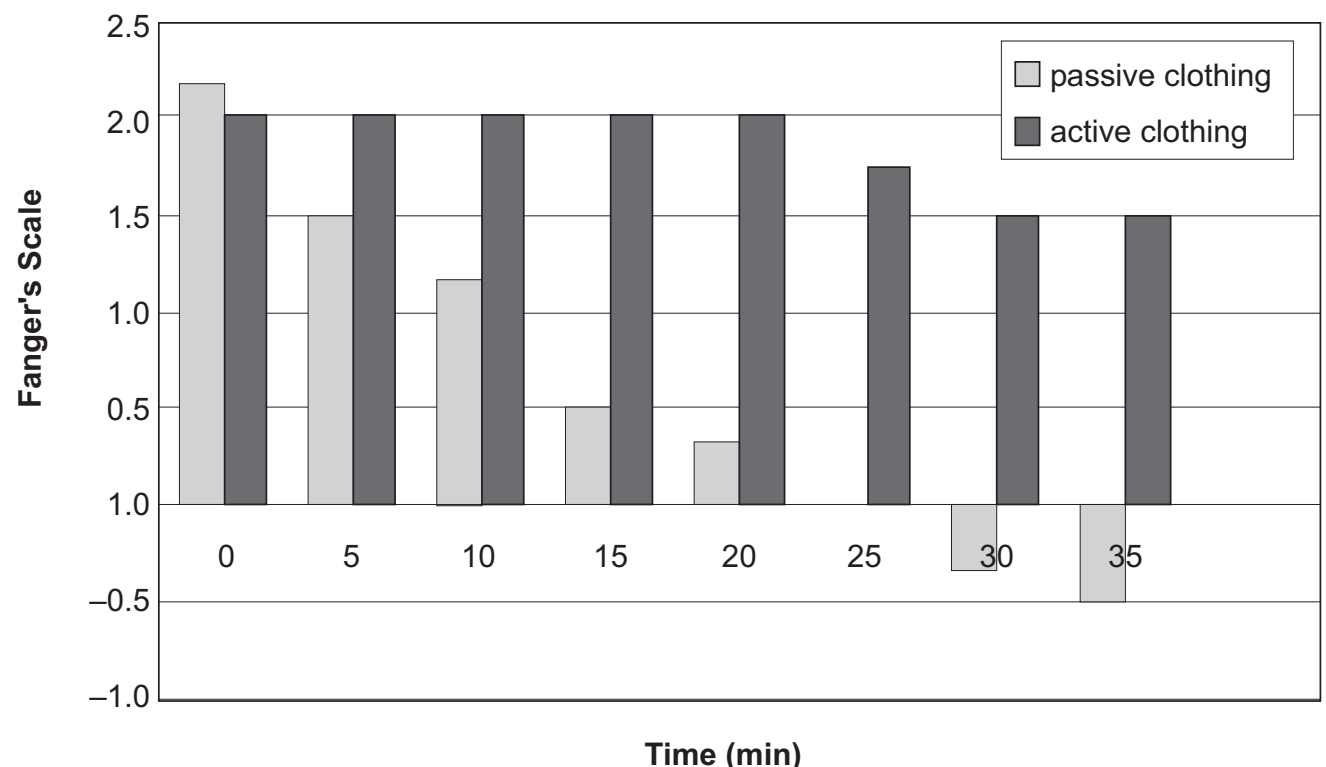

Figure 6. Subjective assessment of thermal sensation during light work in active and passive clothing. Notes. Responses of 6 subjects have been averaged.

reported by the subjects working in variants I and II of the tested clothing. All 6 subjects reported greater thermal comfort in active than in passive clothing (Figure 6). After 45 min of tests in active clothing, the subjects reported feeling warm or natural, whereas tests in clothing providing constant insulation were discontinued after 20-30 min because the subjects were cold.
During the tests, the heating system switched itself on and off if changes in skin and ambient temperatures took place within the specified time of $1 \mathrm{~min}$.

The subjects' HR throughout the whole test cycle was slightly raised in comparison with the baseline value. The changes, however, were insignificant and therefore could not be used for 
assessment of the working load, which could have been due to the fact that the test subjects were very fit.

\section{DISCUSSION}

During the LW and MW tests, 6 subjects worked in two variants of clothing: passive (variant I) and active (variant II); a decrease in skin temperature in time was observed. This indicates a too low thermal insulation level provided by the outer garment at $-24^{\circ} \mathrm{C}$.

However, both in the LW and MW versions of the test, the temperature gradient in time corresponding to the graph slope was higher when the subject worked in clothing with passive insulation than in clothing with variable thermoinsulation. Because of the active heating system, the insulating properties of the garment were improved and heat loss was slower. The difference was higher in LW than in MW because in LW the subject's body produced less heat.

The lowest differences between temperatures were observed on the shoulder and thigh in MW. This may be due to the fact that the tests involved intensive walking and shoulder work during which considerable heat was emitted by the muscles of the extremities. A trend in changes in the cooling effect was observed especially in subjective responses; however, the differences were not statistically significant. Perhaps this was so because the tests were performed in real conditions at workstands in a cold store. The results could be statistically significant if the tests were carried out in more controlled conditions like in a climatic chamber with more participants walking on a treadmill.

\section{CONCLUSIONS}

According to the data presented in section 5, the temperature gradient and the subjective responses, there are advantages of working in an active garment in a cold environment, especially if work causes changes in the subject's metabolic rate. Even though there were no significant differences in skin temperature in the four measuring sites, the subjective responses showed significant differences between work in passive and active garments. According to the subjects, active clothing provided thermal comfort when work involved a variable metabolic rate at $-24{ }^{\circ} \mathrm{C}$.

Further research in this area is required: changes in the thermal insulation of clothing should be studied, and there should be laboratory tests of the skin temperature effect in different environmental temperatures. Moreover, more subjects should be involved. This work will be continued in a new project in 2008-2010.

\section{REFERENCES}

1. Parsons KC. Human thermal environments. London, UK: Taylor \& Francis; 2003.

2. Krause M. Thermodynamics of human body. Ergonomia. 1997;20(1):7-13.

3. Bird RB, Stewart WE, Lightfoot EN. Transport phenomena. New York, NY, USA: Wiley; 2001.

4. Lienhard JH IV, Lienhard JH V. A heat transfer textbook. Cambridge, MA, USA: Phlogiston Press; 2003.

5. Taler J, Duda P. Rozwiązywanie prostych i odwrotnych zagadnień przewodzenia ciepła. Warszawa, Poland: WNT; 2003.

6. Rissanen S, Rintamaki H. Thermal responses and physiological strain in men wearing impermeable and semipermeable protective clothing in the cold. Ergonomics. 1997; 40(2):141-50.

7. Scott RA. Fibres, textiles and materials for future military protective clothing. In: Kuklane K, Holmér I, editors. Proceedings of NOKOBETEF 6 and 1st European Conference on Protective Clothing (Arbete och Hälsa No. 2000:08). Stockholm, Sweden: National Institute for Working Life;2000. p. 108-113. Retrieved February 5, 2008, from: https://gupea.ub.gu.se/dspace/ bitstream/2077/4246/1/ah2000_08.pdf

8. Pause B. Tailored to the purpose: computeroptimized development of thermoregulated activewear. In: Avantex 2001 [CD-ROM]. Frankfurt, Germany: Messe Frankfurt; 2001.

9. Andrzejewska A. Thermographic study on hand cooling process caused by 
vasoconstriction in a cold environment. In: Podgórski D, Majchrzycka K, Pleban D, editors. Proceedings of the International Conference. Research and standardization in the field of development and use of personal protective equipment. Warszawa, Poland: Central Institute for Labour Protection - National Labour Institute; 2005. p. 57-62.

10. Castellani JW, Young AJ, Kain JE, Rouse A, Sawka MN. Thermoregulation during cold exposure: effects of prior exercise. J Appl Physiol. 1999;87(1):247-52.

11. Saat M, Sirisinghe RG, Singh R, Tochichara Y. Decay of heat acclimation during exercise in cold and exposure to cold environment. Eur J Appl Physiol. 2005;95:313-20.

12. European Committee for Standardization (CEN). Protective clothing. General requirements (Standard No. EN 340:2003). Brussels, Belgium: CEN; 2003.

13. Jeong WS, Tokura H. Different thermal conditions of the extremities affect thermoregulation in clothed man. Eur $\mathrm{J}$ Appl Physiol. 1993;67:481-5.
14. Marszałek A, Sołtyński K, Sawicka A. Physiological method of evaluating protective clothing for work in a cold environment. International Journal of Occupational Safety and Ergonomics (JOSE). 1995;3(1):235-243.

15. Gavhed DCE, Holmér I. 1996. Physiological and subjective responses to thermal transients of exercising users dressed in cold-protective clothing. Eur J Appl Physiol. 1996;73:573-81.

16. Bartkowiak G. Dynamics of microclimate depending on physical parameters of clothing packet under protective barrier [doctoral dissertation]. Warszawa, Poland: Central Institute for Labour Protection; 2000.

17. European Committee for Standardization (CEN). Ergonomics of the thermal environment. Analytical determination and interpretation of thermal comfort using calculation of the PMV and PPD indices and local thermal comfort criteria (Standard No. EN ISO 7730:2005). Brussels, Belgium: CEN; 2005. 
